\title{
E-Preferred Approval Plans - Is This the Right Choice for an Academic Library?
}

\section{Simona Tabacaru, Texas A\&M University}

\section{About the Study}

Texas A\&M University (TAMU) Libraries implemented an e-preferred approval plan in December 2010. To identify the impact of the epreferred approval plan on the library's monograph collections, an Solutions in the past seven fiscal years was conducted. Acquisition and usage data were anzed in the context of the subject-specific collection development policies maintained by the TAMU Libraries.

The goal was to determine whether eBooks effectively support the TAMU programs and to what extent hybrid print and e-collections should co-exist to support diverse user information needs.

\section{Methodology}

Title lists were obtained from GOBI database - library activity reports for invoiced orders covering seven fiscal years (September 1, 2010 August 31, 2017)

Circulation data for print monographs was obtained from Voyager, the TAMU Libraries' integrated system, using MS Access queries. Usage data (COUNTER Book Reports 1 and Book Reports 2) for eBooks were obtained from 20 eBook suppliers.

- Cost data was obtained from GOBI database and Voyager. monograph titles by the existing 73 subject-specific $C D$ policies. The CD policies closely mirror the TAMU programs.

The study identified approval plan budget expenditure trends and investigated the $\%$ of approval plan print and eBook titles used by subject areas as defined in the TAMU Libraries' CD Policies.

\section{$\%$ of Monographs Approval Plan} Budget Spent on eBooks

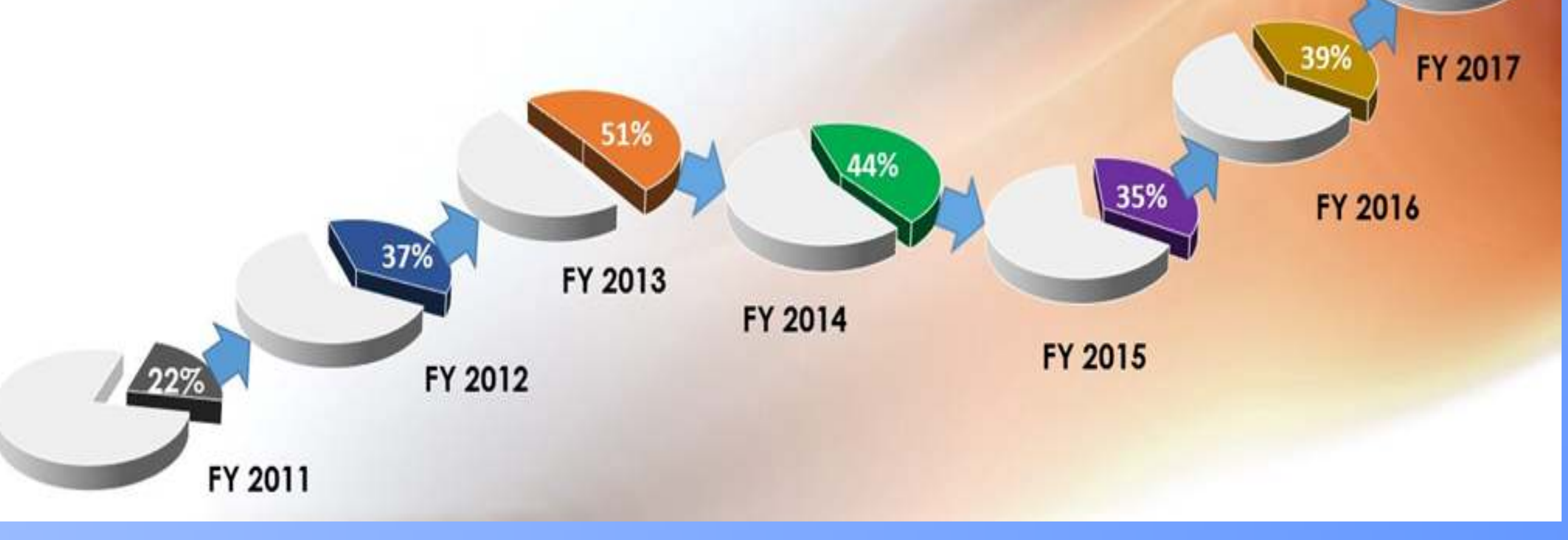

Comparison of Use Rate for Purchased Print and eBooks by Acquisition Method

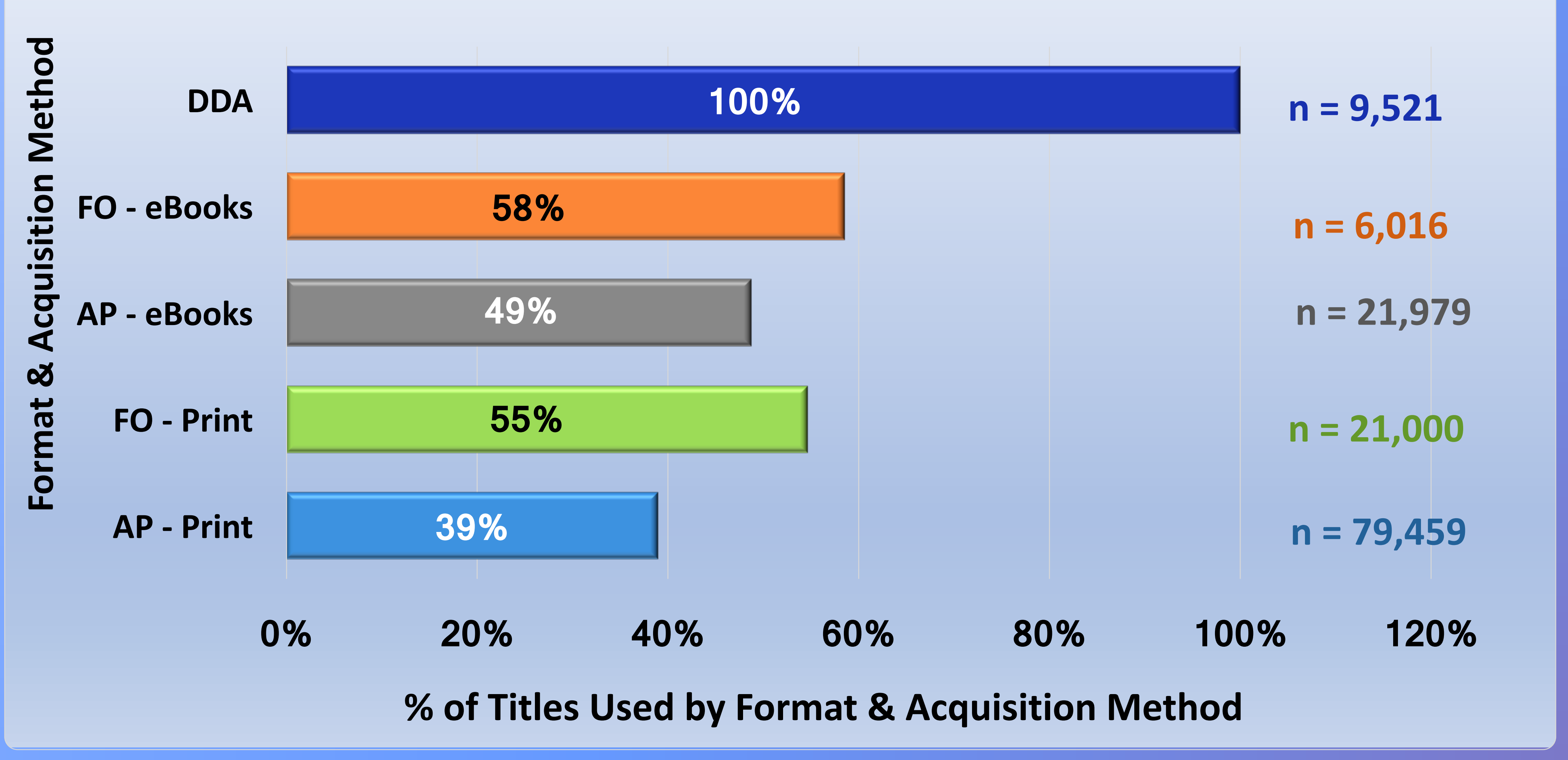

Monograph Items Purchased from GOBI Library Solutions

FY2011 - FY2017

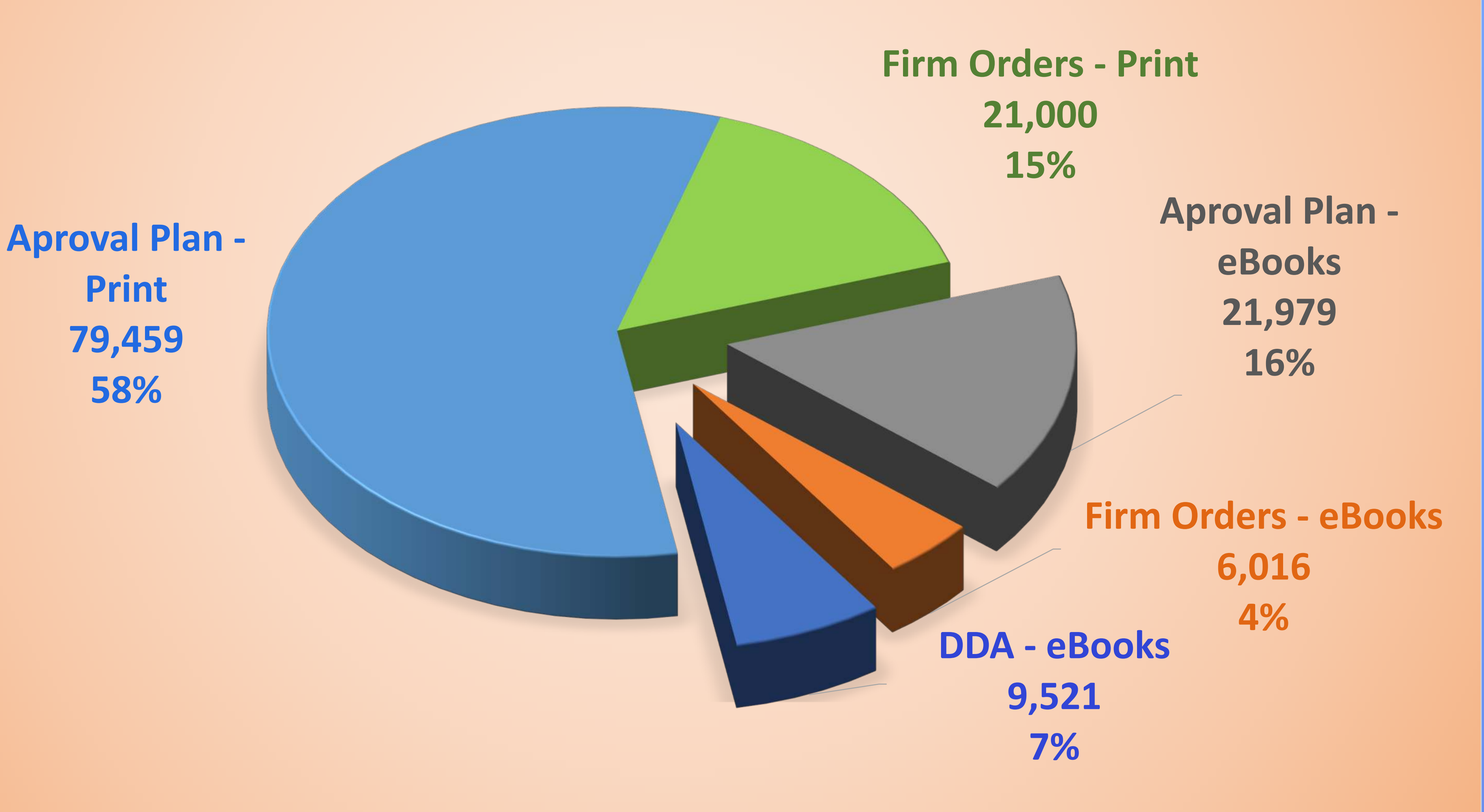

Acquisition Trend - Approval Plan

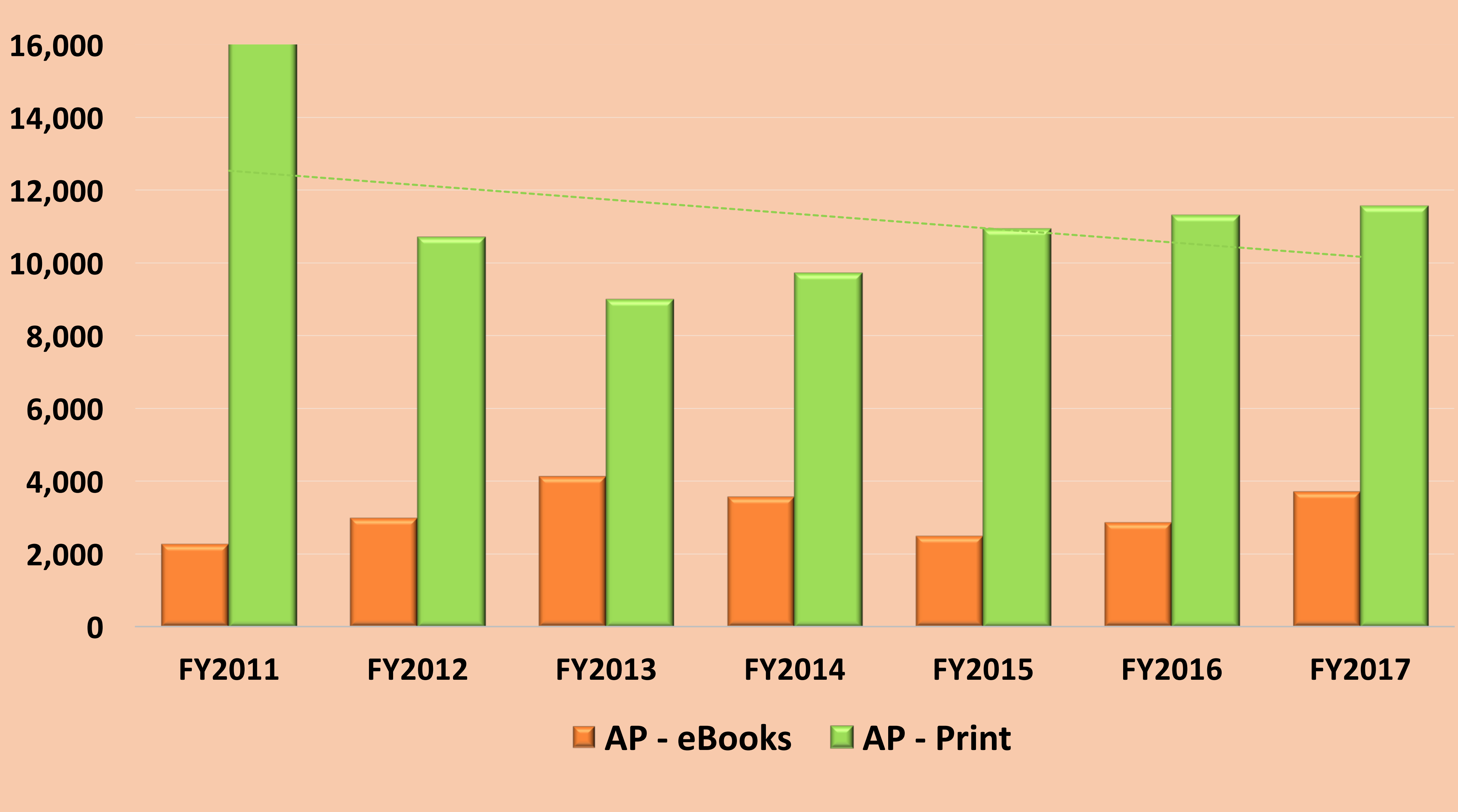

Table - Comparison of Use Rate for Approval Plan Print and eBooks by CD Policy

\begin{tabular}{|c|c|c|c|c|c|c|c|}
\hline \multirow[b]{2}{*}{$\begin{array}{l}\text { Collection Development } \\
\text { Policy - eBook Preferred }\end{array}$} & \multicolumn{3}{|c|}{ AP - Print } & \multicolumn{3}{|c|}{ AP - eBooks } & \multirow[b]{2}{*}{$\begin{array}{l}\text { Use Rate } \\
\text { Differenc }\end{array}$} \\
\hline & $\begin{array}{c}\text { Number of } \\
\text { Titles } \\
\text { Acquired }\end{array}$ & $\begin{array}{c}\text { Total Titles } \\
\text { Used }\end{array}$ & $\begin{array}{l}\% \text { Tittes } \\
\text { Used }\end{array}$ & $\begin{array}{c}\text { Number of } \\
\text { Titles } \\
\text { Acquired }\end{array}$ & $\begin{array}{l}\text { Total } \\
\text { Titles } \\
\text { Used }\end{array}$ & $\begin{array}{l}\text { \% Titles } \\
\text { Used }\end{array}$ & \\
\hline \multicolumn{8}{|c|}{ Top 5 CD Policies with higher eBooks use rates compared to print books } \\
\hline Management & 1,214 & 413 & $34 \%$ & 1,218 & 661 & $54 \%$ & $20 \%$ \\
\hline Marketing & 447 & 162 & $36 \%$ & 368 & 230 & $63 \%$ & $26 \%$ \\
\hline Chemical Engineering & 381 & 164 & $43 \%$ & 139 & 92 & $66 \%$ & $23 \%$ \\
\hline Chemistry & 173 & 86 & $50 \%$ & 81 & 53 & $65 \%$ & \\
\hline & & & & 100 & 56 & $56 \%$ & $16 \%$ \\
\hline \multicolumn{8}{|c|}{ Top 5 CD Policies with similar use rates for print and eBooks } \\
\hline Library Science & 140 & 79 & $56 \%$ & 49 & 27 & $55 \%$ & $-1 \%$ \\
\hline Middle Eastern & 438 & 122 & $28 \%$ & 152 & 41 & $27 \%$ & $-1 \%$ \\
\hline Sociology & 3,630 & 1,525 & $42 \%$ & 3,185 & 1,329 & $42 \%$ & $0 \%$ \\
\hline Aeronautical Engineering & 96 & 48 & $50 \%$ & 26 & 13 & $50 \%$ & $0 \%$ \\
\hline Astronomy & 232 & 125 & $54 \%$ & 94 & 52 & $55 \%$ & $1 \%$ \\
\hline \multicolumn{8}{|c|}{ Top 5 CD Policies with higher print books use rate compared to eBooks } \\
\hline teorolos & 211 & 108 & $51 \%$ & 156 & 68 & $44 \%$ & $-8 \%$ \\
\hline dsce & $1000+2$ & 74 & $58 \%$ & 18 & 9 & $50 \%$ & $-8 \%$ \\
\hline sics & 453 & 321 & $71 \%$ & 206 & 128 & $62 \%$ & $-9 \%$ \\
\hline General Science & 372 & 200 & $54 \%$ & 245 & 108 & $44 \%$ & $-10 \%$ \\
\hline Agriculture, General & 116 & 57 & $49 \%$ & 88 & 31 & $35 \%$ & $-14 \%$ \\
\hline
\end{tabular}

Monograph Items Purchased on Approval Plan by CD Policies' Preferred Format

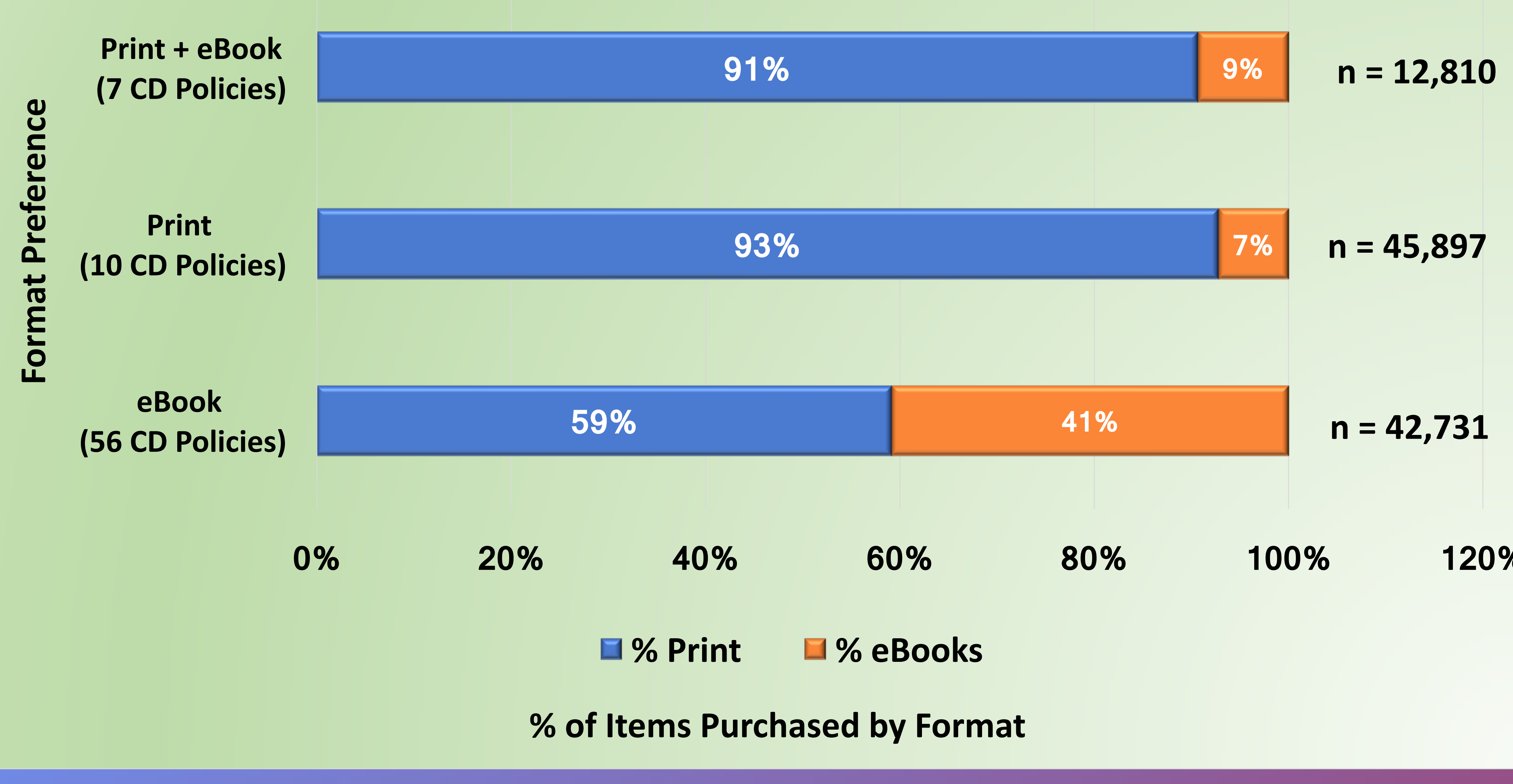

\section{Conclusions}

Overall, $73 \%$ of the monographs purchases from GOBI Library Solutions in FY2011-FY2017 were print items and 27\% were eBooks.

For the 56 subject areas that have eBook as preferred format, only $41 \%$ of the items received on the approval plan in FY2011-FY2017 were eBooks. This is an indicator of the low percentage of eBooks that are released simultaneously with their print counterpart by publishers.

While only $21 \%$ of approval plan purchases are eBooks, the money spent on Books varies between $22 \%$ and $51 \%$ on the approval plan budget, with an increasing trend in the past three fiscal years.

Overall, eBooks received higher use rates than print books. However, approval plan eBooks tend to receive less usage compared to firm-ordered eBooks, and firm-ordered eBooks tend to receive less usage than DDA eBooks.

Of the 73 subject areas (CD Policies), 16 subjects have a higher use rate in print than in electronic format. Surprises: General Science, Physics, and Meteorology.

19 subject areas have similar use rates in both formats (less than $5 \%$ circulation rate difference). These are subject areas that might require both formats to satisfy user needs.

In 15 subject areas TAMU Libraries acquired less than 100 print books or - Brooks on the approval plan over a saven-year period. These subjects should be reviewed to determine whether adequate support is provided to the respective TAMU programs. Are these separate collection development policies needed for these subjects or should they be folded into broader existing subject areas?

Some print-only approval subject areas have high eBook usage rates. To analysis of firm orders and DDA purchases is underway.

Overall, the e-preferred approval plan seems to adequately support the TAMU programs, although deeper analysis is needed to determine why some subject areas have lower use rates than other. 